\title{
Discrete Forebrain Neuronal Networks Supporting Noradrenergic Regulation of Sensorimotor Gating
}

\author{
Karen M Alsene ${ }^{1,3}$, Abha K Rajbhandari ${ }^{1,3}$, Marcia J Ramaker ${ }^{2}$ and Vaishali P Bakshi*,' \\ 'Department of Psychiatry and Neuroscience Training Program, University of Wisconsin-Madison, Madison, WI, USA; ${ }^{2}$ OHSU Department \\ of Behavioral Neuroscience, Portland, OR, USA
}

\begin{abstract}
Prepulse inhibition (PPI) refers to the reduction in the startle response when a startling stimulus is preceded by a weak prestimulus, and is an endophenotype of deficient sensorimotor gating in several neuropsychiatric disorders. Emerging evidence suggests that norepinephrine (NE) regulates PPI, however, the circuitry involved is unknown. We found recently that stimulation of the locus coeruleus (LC), the primary source of NE to the forebrain, induces a PPI deficit that is a result of downstream NE release. Hence, this study sought to identify LC-innervated forebrain regions that mediate this effect. Separate groups of male Sprague-Dawley rats received a cocktail solution of the $\alpha$ I-NE receptor agonist phenylephrine plus the $\beta$-receptor agonist isoproterenol (equal parts of each; 0, 3, I0, and $30 \mu \mathrm{g}$ ) into subregions of the medial prefrontal cortex (mPFC), nucleus accumbens (NAcc), extended amygdala, mediodorsal thalamus (MD-thalamus), or the dorsal hippocampus (DH) before PPI testing. NE agonist infusion into the posterior mPFC, NAcc shell, bed nucleus of the stria terminalis, basolateral amygdala, and the MD-thalamus disrupted PPI, with particularly strong effects in MD-thalamus. Sites in which NE receptor stimulation did not disrupt PPI (anterior mPFC, NAcc core, central amygdala, and DH) did support PPI disruptions with the dopamine D2 receptor agonist quinpirole $(0,10 \mu \mathrm{g})$. This pattern reveals new pathways in the regulation of PPI, and suggests that NE transmission within distinct thalamocortical and ventral forebrain networks may subserve the sensorimotor gating deficits that are seen in disorders such as schizophrenia, Tourette syndrome, and post-traumatic stress disorder.

Neuropsychopharmacology (20II) 36, I003-1014; doi:10.1038/npp.2010.238; published online 19 January 20II
\end{abstract}

Keywords: norepinephrine; noradrenaline; locus ceruleus; limbic; antipsychotic; attention

\section{INTRODUCTION}

Sensorimotor gating is a fundamental form of informationprocessing permitting organisms to filter information from external and internal domains, and is presumed deficient in multiple psychiatric disorders in which there is a failure to filter cognitive, sensory, or motor information (Braff et al, 2008; Geyer, 2008; Swerdlow et al, 2008). Prepulse inhibition (PPI), referring to the inhibition by a weak pre-stimulus (prepulse) of the startle response to a subsequent intense stimulus (pulse), measures sensorimotor gating, and patients with disorders involving deficient sensorimotor gating show deficits in PPI (Braff et al, 2001). Thus, studying PPI in animal models provides a useful tool for delineating the neural circuitry underlying clinically observed deficits in sensorimotor gating, and may help to

\footnotetext{
*Correspondence: Dr VP Bakshi, Department of Psychiatry, University of Wisconsin School of Medicine and Public Health, 600I Research Park Boulevard, Madison, WI 53719, USA, Tel: +608-265-6062, Fax: + 608-265-3050, E-mail: vbakshi@wisc.edu

${ }^{3}$ These authors contributed equally to this work.

Received 2 September 20 I0; revised 22 November 20 0; accepted 2 December 2010
}

identify the neural substrates for information-processing disturbances in a number of psychiatric illnesses (Geyer et al, 2001; Swerdlow et al, 2001).

Noradrenergic (NE) substrates of PPI are not well characterized, which is surprising given the proposed role of $\mathrm{NE}$ in regulating attention, arousal, and cognition (Arnsten, 2004; Aston-Jones and Cohen, 2005; Berridge and Waterhouse, 2003; Sara, 2009). Recent findings indicate that NE receptors regulate PPI (Alsene et al, 2006; Carasso et al, 1998; Lahdesmaki et al, 2002, 2004; Sallinen et al, 1998), and that stimulation of the locus coeruleus (LC), the major source of $\mathrm{NE}$ to forebrain (Foote et al, 1983), produces an anatomically and behaviorally specific deficit in PPI that is independent of dopamine (DA) or serotonin transmission, is reversed preferentially by second-generation antipsychotics, and is mediated by downstream NE release (Bakshi and Alsene, 2010). The specific NEinnervated terminal fields through which these effects are produced, however, remain unknown.

Sites throughout the neuraxis receive NE input; many of these regions previously have been found through lesion or pharmacological studies to regulate PPI, but to what extent NE is involved is unknown (Berridge and Waterhouse, 2003; 
Schwabe and Koch, 2004; Swerdlow et al, 2001). Among these are portions of the medial prefrontal cortex (mPFC), ventral striatum, extended amygdala, hippocampus, and thalamus, all of which contain NE-synthesizing nerve terminals and significant concentrations of the main postsynaptic adrenoceptors and NE heteroreceptors $(\alpha 1$ and $\beta$ ) (Bylund et al, 1994; Foote et al, 1983; McCune et al, 1993; Nicholas et al, 1996; Palacios and Kuhar, 1982; Pieribone et al, 1994; Pupo and Minneman, 2001; Rainbow et al, 1984). Hence, this study was designed to map the forebrain sites at which infusions of an $\alpha 1+\beta$-adrenoceptor cocktail (stimulating non-autoreceptor NE receptors) disrupted PPI. This investigation provides a crucial step in delineating the substrates through which NE transmission regulates PPI and as such has the potential to identify novel pathways underlying the sensorimotor gating deficits seen in numerous psychiatric illnesses in which NE signaling abnormalities are hypothesized (Braff et al, 2001; Daly et al, 2005; Dvorakova et al, 2007; Hornykiewicz, 1982; Southwick et al, 1993).

\section{SUBJECTS AND METHODS}

\section{Animals}

A total of 134 male Sprague-Dawley rats (Harlan Laboratories, Madison, WI) weighing 300-400 g were housed in pairs in clear cages with ad libitum access to food and water in a light- and temperature-controlled vivarium, and were maintained under a 12-h light-dark cycle (lights on at 0700 hours). All facilities and procedures were in accordance with the guidelines regarding animal use and care from the NIH of the United States, and were supervised and approved by the Institutional Animal Care and Use Committee of the University of Wisconsin.

\section{Surgery \\ Rats were anesthetized with ketamine/xylazine $(80 \mathrm{mg} /$ $12 \mathrm{mg}$ per ml; Phoenix Scientific, St Joseph, MO), and secured in a stereotaxic frame (Kopf Instruments, Tujunga, CA). Stainless steel cannulae (23-gauge, Small Parts, Miami Lakes, FL) were implanted and affixed to the skull with dental cement (Lang Dental Mfg, Wheeling, IL) and anchoring skull screws (Plastics One, Roanoke, VA) and were aimed bilaterally at sites using the atlas of Paxinos and Watson (1998). Final coordinates in $\mathrm{mm}$ from bregma were: anterior mPFC ( +3.0 AP, $\pm 0.75 \mathrm{LM},-4.1 \mathrm{DV})$; posterior mPFC ( +2.0 AP, $\pm 0.8 \mathrm{LM},-4.0)$; nucleus accumbens shell (NAccSh, +1.7 AP, $\pm 0.8 \mathrm{LM},-7.5 \mathrm{DV}$ ); nucleus accum- bens core (NAccCo, +1.3 AP, \pm 2.0 LM, $-7.1 \mathrm{DV}$ ); mediodorsal thalamus (MD-thalamus, $-3.0 \mathrm{AP}, \pm 0.8 \mathrm{LM}$, $-5.6 \mathrm{DV}$ ); bed nucleus of the stria terminalis (BNST, at an $11^{\circ}$ angle from the midline, $\left.-0.8 \mathrm{AP}, \pm 2.7 \mathrm{LM},-6.7 \mathrm{DV}\right)$; dorsal hippocampus (DH, $-3.3 \mathrm{AP}, \pm 2.0 \mathrm{LM},-3.6 \mathrm{DV})$; central nucleus of amygdala (CeA, $-2.1 \mathrm{AP}, \pm 3.85,-7.9$ $\mathrm{DV}$ ); and basolateral amygdala (BLA, $-3.0 \mathrm{AP}, \pm 4.8 \mathrm{LM}$, $-8.3 \mathrm{DV})$. Wire stylets were placed in the cannulae to prevent blockage, and rats recovered for a week before testing.}

\section{Drugs and Microinfusions}

All drugs $(( \pm)$-phenylephrine hydrochloride, $( \pm)$-isoproterenol hydrochloride, and (-)-quinpirole hydrochloride) were obtained from Sigma (St Louis, MO) and dissolved in sterile isotonic saline. Doses were calculated as salts based on previous studies (Berridge et al, 2003), and the infusion volume for all experiments was $0.5 \mu \mathrm{l}$ per side.

For microinfusions, stylets were removed and cannulae were cleaned with a dental broach (Henry Schein, Melville, NY); stainless steel injectors (30-gauge, Small Parts) were lowered to extend $2.0 \mathrm{~mm}$ past the tip of the cannula (DV coordinates reflect distance from skull surface to the injector tip after insertion). Injectors were attached with polyethylene tubing (PE-10, Becton Dickinson, Sparks, MD) to $10-\mu \mathrm{l}$ glass Hamilton syringes (Hamilton, Reno, NV) mounted on a microdrive pump (Harvard Apparatus, Holliston, MA). After infusions, injectors were left in place for $1 \mathrm{~min}$ to allow for absorption of the solution before replacement of stylets.

\section{Startle Chambers}

Startle chambers (San Diego Instruments, San Diego, CA) contained a nonrestrictive Plexiglas cylinder resting inside a ventilated and illuminated sound-attenuating cabinet, with a high-frequency loudspeaker to produce all acoustic stimuli. As described previously (Mansbach et al, 1988), the whole-body startle response of the animal caused vibrations, which were then converted into analog signals by a piezoelectric unit attached to the platform. These signals were digitized and stored by a microcomputer and interface unit. Monthly calibrations were performed on the chambers to ensure accuracy of the sound levels and measurements. Sound levels were measured using the $\mathrm{dB}(\mathrm{A})$ scale.

\section{Startle and PPI Testing}

The test session consisted of a background noise $(65 \mathrm{~dB})$ that was presented alone for $5 \mathrm{~min}$ and remained on for the length of the session, followed by presentation (in a pseudorandom order) of pulse-alone trials $(40-\mathrm{ms}, 120-\mathrm{dB}$ broadband bursts), prepulse + pulse trials (20-ms noises that were 3 , 9, or $15 \mathrm{~dB}$ above the background noise and were presented $100 \mathrm{~ms}$ before the onset of the 120 -dB pulse), and no stimulus trials (only the background noise). The session was divided into two equivalent parts that each contained 40 trials (8 each of the 3-, 9-, and 15-dB prepulse + pulse trials, 8 pulse-alone trials and 8 no stimulus trials). Four pulsealone trials were presented at the beginning and the end of the session to ensure that startle magnitude was stable during the portion of the session when PPI was measured, as the most rapid habituation of the startle response occurs within the first several presentations (Geyer et al, 1990); these pulse-alone trials were excluded from the calculations of startle and \%PPI. During the week before the drug testing began, all rats underwent one exposure to the startle test session per day on 3 separate days with sham infusions preceding the last test to familiarize rats with the testing and microinfusion procedures before the commencement of drug testing. 


\section{Experimental Design}

Each experiment tested the effects of microinfusions of a mixed NE receptor agonist cocktail $(\alpha 1$ and $\beta)$ in a specific brain region, using separate sets of experimentally naïve rats for each site. Rats were given microinfusions of an equal parts cocktail of the $\alpha 1$-receptor agonist phenylephrine plus the $\beta$-receptor agonist isoproterenol $(0,3,10$, or $30 \mu \mathrm{g} / 0.5 \mu \mathrm{l})$ into either the anterior $\operatorname{mPFC}(N=10)$, posterior mPFC $(N=8)$, NAccSh $(N=10)$, NAccCo $(N=8)$, MD-thalamus $(N=7)$, BNST $(N=6)$, DH $(N=8)$, CeA $(N=12)$, or the BLA $(N=13)$ immediately before testing in the startle chambers. For each experiment, doses were administered in a counterbalanced order with at least 2 days separating consecutive tests. For all of the sites in which no effect of the NE receptor agonists was found, an additional study was done to determine if the DA D2 receptor agonist quinpirole would produce any effect. Thus, separate groups of experimentally naïve rats received either saline or quinpirole $(10 \mu \mathrm{g} / 0.5 \mu \mathrm{l})$ into either the anterior mPFC $(N=13)$, NAccCo $(N=16), \mathrm{DH}(N=8)$, and CeA $(N=15)$ immediately before testing in startle chambers; the treatments were given in a counterbalanced order over 2 test days that were separated by $72 \mathrm{~h}$.

\section{Histology}

At the end of all experiments, rats were perfused transcardially with $10 \%$ formalin in phosphate buffer (Sigma Diagnostics, St Louis, MO), 60- $\mu \mathrm{m}$ brain sections were taken through the injection site and stained with cresyl violet, and placements were verified by an experimenter blind to the behavioral data; rats with missed placements were excluded from subsequent behavioral analyses. Sample sizes for each experiment reflect this final adjusted number.

\section{Data Analysis}

The startle response to the onset of the 120-dB burst was recorded for $100 \mathrm{~ms}$ for each pulse-alone, prepulse + pulse, and from the onset of each no stimulus trial. Two measurements (startle magnitude and PPI) were calculated from these values for each rat for each of the different treatment conditions. Startle magnitude was the average of the startle responses to all pulse-alone trials. PPI was calculated as a percent score for each prepulse + pulse trial type: $\% \mathrm{PPI}=100-(($ startle response for prepulse + pulse trial)/(startle response for pulse-alone trial)). Post hoc analyses were done using Newman-Keuls tests. The $\alpha$-level for significance was set at 0.05 .

\section{RESULTS}

For every experiment, a significant main effect of prepulse intensity was seen on analyzing \%PPI data (F-ratios $\geqslant 35$, $P$-values $<0.001)$; this is a standard parametric feature of PPI in which increasing prepulse intensities elicit higher levels of PPI (Braff et al, 2001). For the sake of brevity, this main effect is not repeated throughout the Results section, as there also were no significant interactions between the prepulse intensity and drug factors for any experiment.
Stimulation of $\alpha 1+\beta$-NE Receptors in Discrete Forebrain Regions Disrupts PPI

Medial prefrontal cortex. ANOVA revealed a significant main effect of the $\alpha 1+\beta$-NE receptor agonist cocktail on PPI in the posterior mPFC $(\mathrm{F}(3,21)=6.3, P<0.003)$, but not the anterior $\operatorname{mPFC}(\mathrm{F}(3,27)=0.6$, NS). Post hoc analyses indicated that the highest dose reduced PPI levels significantly below vehicle levels at each prepulse intensity in the posterior mPFC $(P<0.05)$ (Figure 1).

Nucleus accumbens. Differential effects on PPI with NE receptor stimulation were also obtained across NAcc subregions (Figure 2), with a significant main effect of $\mathrm{NE}$ agonist treatment in NAccSh $(\mathrm{F}(3,27)=2.9, P<0.048)$, but not in NAccCo $(F(3,21)=0.6$, NS). Subsequent analyses confirmed that in the NAccSh, the highest dose of the cocktail reduced PPI at the $9-\mathrm{dB}(P<0.05)$ and $15-\mathrm{dB}$ $(P<0.01)$ prepulse intensities.

BNST. A significant main effect of drug was seen in the BNST $(F(3,15)=6.4, P<0.006)$, (Figure 3 ), with reduction of PPI at each prepulse intensity after administration of the highest dose of the cocktail $(P<0.05-P<0.01)$.

Amygdala. Heterogeneity in the response to NE receptor stimulation also was seen across subregions of the amygdala (Figure 4), with significant main effects of drug treatment in the BLA $(\mathrm{F}(3,36)=3.3, P<0.030)$, but not in the CeA $(\mathrm{F}(3,33)=0.3$, NS $)$. In the BLA, the highest dose reduced PPI at the lower two prepulse intensities $(P<0.05)$; at the $9-\mathrm{dB}$ intensity, the $10-\mu \mathrm{g}$ dose in BLA also reduced PPI $(P<0.05)$. For these sites, a number of rats had injector placements that fell just outside of either amygdala subregion; these subjects were thus not included in the above groups. Instead, their behavioral data were analyzed separately in order to determine if $\mathrm{NE}$ receptor agonist infusions immediately outside of the BLA and CeA affected PPI. Neither the 'missed-BLA' group $(N=7)$ nor the 'missed-CeA' group $(N=4)$ showed any significant drug treatment effect ( $\mathrm{F}$ ratios for main effects or interactions $\leqslant 0.5, P$-values $\geqslant 0.7)$, indicating that the PPI-disruptive effect that was observed following NE agonist infusion into the BLA was highly anatomically specific.

Thalamus and hippocampus. The $\alpha 1+\beta$-receptor cocktail produced a significant main effect of drug treatment in the MD-thalamus $(\mathrm{F}(3,18)=12.6, P<0.001)$, but not in the $\mathrm{DH}(\mathrm{F}(3,21)=0.5$, NS). Post hoc analyses indicated that in MD-thalamus, both the $10-\mu \mathrm{g}(P<0.05)$ and the $30-\mu \mathrm{g}$ $(P<0.01)$ doses reduced PPI at all three prepulse intensities; this effect in MD-thalamus was the strongest of all sites examined (Figure 5). In particular, comparison of the efficacy of the middle dose to disrupt PPI indicated that in MD-thalamus, this dose produced a $30 \%$ reduction in composite PPI from vehicle values, which was nearly double the PPI reduction produced by this dose in the BLA (the only other site in which the $10-\mu \mathrm{g}$ dose had any effect at all). Thus, both in terms of magnitude of the effect size as well as sensitivity to lower doses, the MD-thalamus showed a greater effect than any other site tested. 

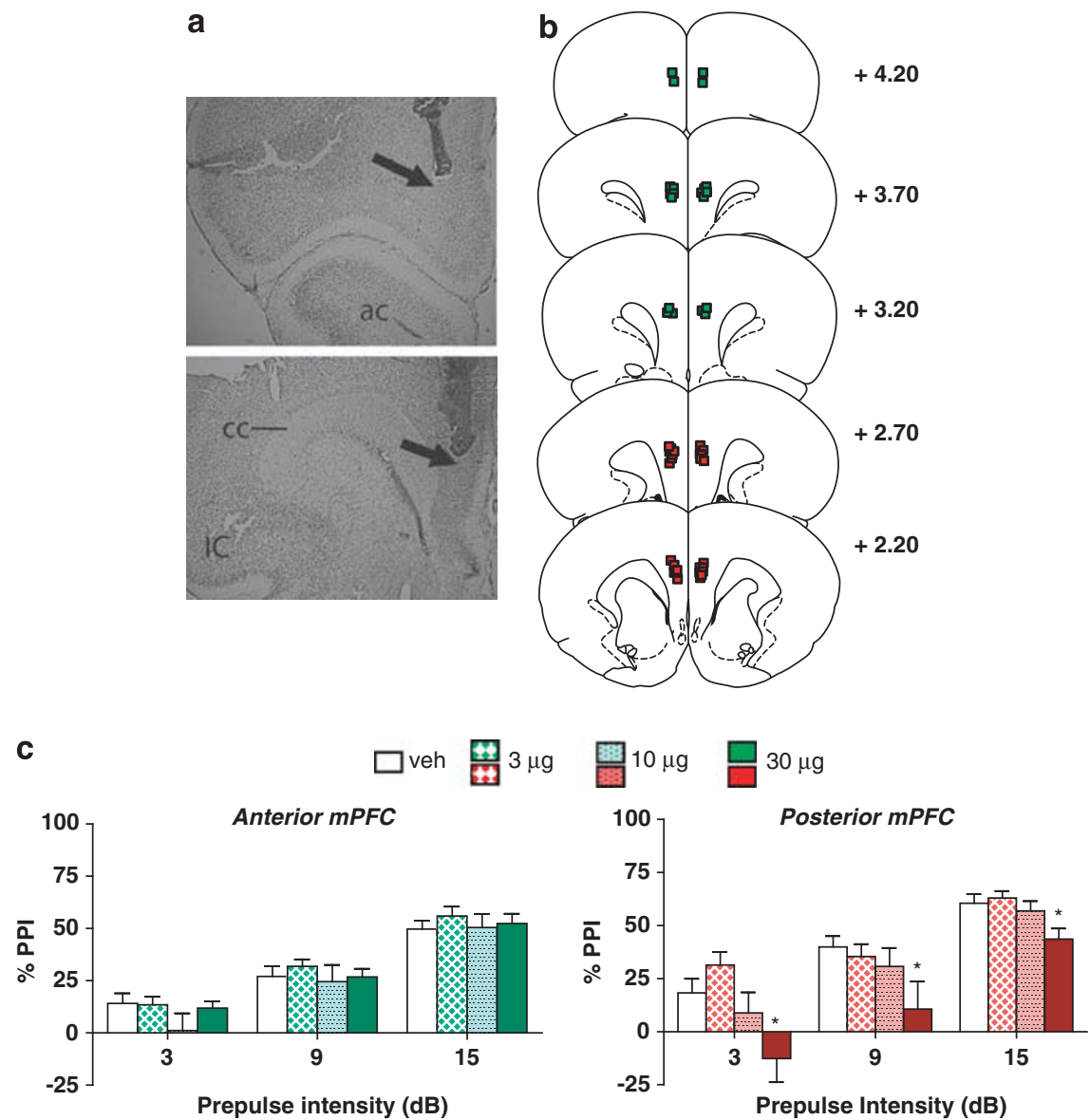

Figure I (a) Representative injector tip locations within the anterior (top panel) and posterior (bottom panel) medial prefrontal cortex (mPFC), indicated by the arrows. ac, anterior commissure; IC, insular cortex; cc, corpus callosum. (b) Chartings depicting the locations in which infusions of the $\alpha I+\beta$-NE receptor agonist cocktail did (red) and did not (green) disrupt \% prepulse inhibition (PPI). Distances are in $\mathrm{mm}$ from the bregma. (c) Effects on \% PPI of the phenylephrine + isoproterenol cocktail in the anterior and posterior mPFC. Values represent means \pm SEM for each dose. Doses are in $\mu g / 0.5 \mu$. Prepulse intensity indicates decibels above the background noise level. $* P<0.05$, relative to $\mathrm{VEH}$ (vehicle) condition.

There was some variability in the non-drug (vehicle) levels of PPI and startle across brain regions, which either could be due to the differential patterns of tissue damage that would be incurred by targeting the different sites or that simply reflects the regular variability in baseline values from one cohort of rats to another. Nevertheless, because a within-subjects design was used for each study, this small variability in baseline values across experiments would not affect the experimental outcomes, because drug and vehicle values were obtained within the same rat.

\section{Sites Unresponsive to NE Receptor Agonists do Support DA D2 Agonist-Induced PPI Disruption}

As a positive control in sites where the NE agonist cocktail did not disrupt PPI, the D2 agonist quinpirole was tested. ANOVA indicated a significant main effect of quinpirole treatment in each of these regions: anterior mPFC $(\mathrm{F}(1,12)=4.7, \quad P<0.049) ; \quad$ NAccCo $\quad(\mathrm{F}(1,15)=8.9, \quad P<$ $0.009)$; $\mathrm{DH}(\mathrm{F}(1,7)=18.6, P<0.004)$; $\mathrm{CeA}(\mathrm{F}(1,14)=6.6$, $P<0.023)$. Post hoc analyses confirmed that quinpirole significantly lowered PPI at multiple prepulse intensities in each site $(P<0.05-P<0.001)$. Thus, the failure of anterior mPFC, NAccCo, DH, or CeA to display NE receptor- mediated PPI deficits is not because of imperviousness to PPI modulation in these regions; rather, it indicates that in these sites, stimulation of DA but not NE receptors disrupts PPI (Figure 6).

\section{Effects on PPI are Dissociable from Changes in Baseline Startle}

Table 1 displays the effects of the phenylephrine $(\alpha 1)$ / isoproterenol $(\beta)$ cocktail on baseline startle values (responses to the pulse-alone trials) in each site; Table 2 gives this information for the quinpirole tests. ANOVA indicated a significant main effect of the NE receptor cocktail on startle responses after infusion into the posterior $\operatorname{mPFC}(\mathrm{F}(3,21)=4.8, P<0.01)$, BLA $(\mathrm{F}(3,36)=5.9$, $P<0.003)$, BNST $(\mathrm{F}(3,15)=3.6, \quad P<0.04), \quad$ and $\mathrm{CeA}$ $(\mathrm{F}(3,33)=2.8, P<0.05)$; post hoc analyses revealed that the highest dose reduced startle compared with the vehicle condition $(P<0.05)$ in each of these sites. No significant main effect of the NE receptor cocktail was seen with infusion into any other site (all $\mathrm{F}$ ratios $\leqslant 1.8$ and $P$-values $\geqslant 0.13$ ). A significant main effect of quinpirole treatment was seen after infusion into the anterior mPFC $(\mathrm{F}(1,12)=10.7, \quad P<0.007), \quad$ NAccCo $\quad(\mathrm{F}(1,15)=18.9$, 
a
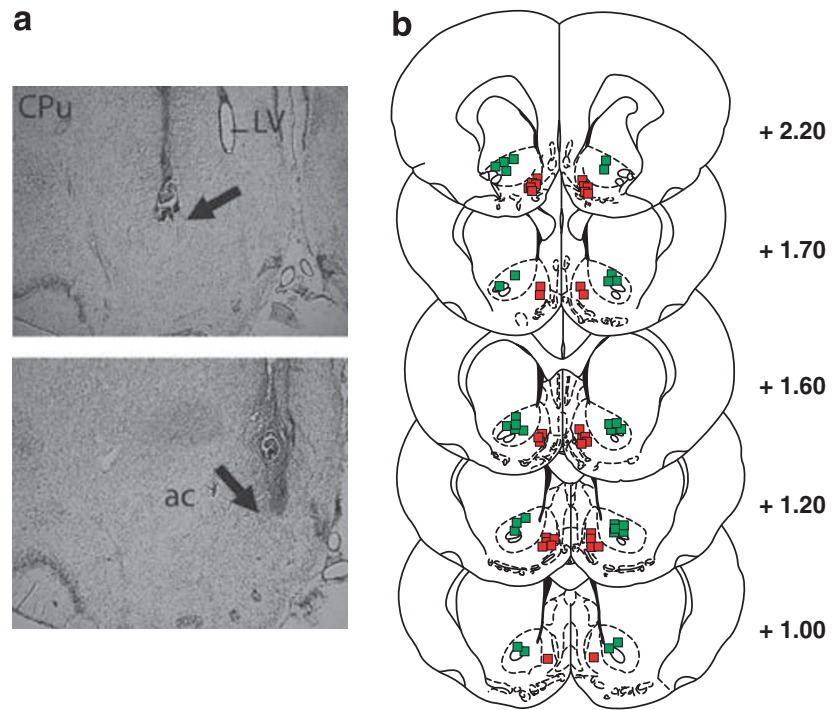
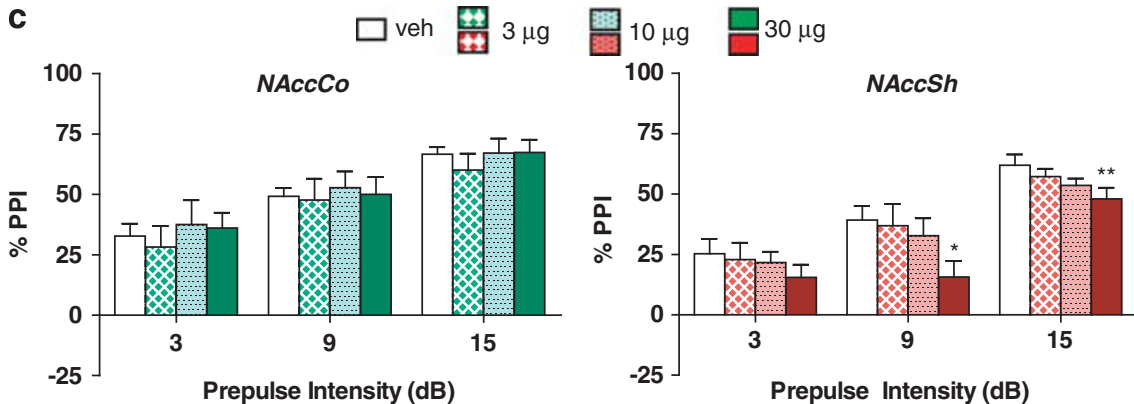

Figure 2 (a) Representative injector tip locations within the nucleus accumbens core (NAccCo) (top panel) and shell (NAccSh) (bottom panel), indicated by the arrows. ac, anterior commissure; CPu, caudate putamen; LV, lateral ventricle. (b) Chartings depicting the locations in which infusions of the $\alpha$ I $+\beta$-NE receptor agonist cocktail did (red) and did not (green) disrupt \% prepulse inhibition (PPI). Distances are in mm from the bregma. (c) Effects on \% PPI of the phenylephrine + isoproterenol cocktail in the NAccCo and NAccSh. Values represent means \pm SEM for each dose. Doses are in $\mu g / 0.5 \mu l$. Prepulse intensity indicates decibels above the background noise level. $* P<0.05$, $* P<0.0$ I relative to $\mathrm{VEH}$ (vehicle) condition.

$P<0.001)$, and $\mathrm{DH}(\mathrm{F}(1,7)=13.1, P<0.009)$, with quinpirole lowering startle in these sites $(P<0.05)$, but not in the CeA.

Therefore, PPI reduction was seen without concomitant startle changes (ie, with cocktail infusion into NAccSh or MD-thalamus or quinpirole infusion into CeA), and in other cases, startle reduction was seen without accompanying alterations in PPI (ie, with cocktail infusion into CeA). Thus, alterations in baseline startle are neither necessary nor sufficient to produce PPI deficits. In order to further confirm this dissociation between startle and PPI effects, additional analyses were conducted for all experiments using a median-split method to divide rats within each experiment into two groups based on the degree of startle suppression induced by the drug treatment relative to the vehicle condition (the 30- $\mu$ g dose of the cocktail, or the quinpirole for the D2 agonist studies). Thus, half of the rats in each experiment were assigned to the 'high suppression' group, and the other half were in the 'low suppression' group. This grouping designation was then included as an additional factor in the original ANOVAs to examine whether the high and low groups showed differential PPI responses with drug treatment. No significant interactions on PPI were seen for the startle suppression grouping factor and the drug treatment factor for any experiment, indicat- ing that the drug-induced PPI deficits were independent of any effect on baseline startle magnitude.

\section{DISCUSSION}

The goal of this study was to identify the forebrain NE terminal fields in which stimulation of $\mathrm{NE}$ receptors (excluding autoreceptors) disrupts PPI. Infusion of an equal parts cocktail of the $\alpha 1-\mathrm{NE}$ receptor agonist phenylephrine and the $\beta$-receptor agonist isoproterenol into posterior mPFC, NAccSh, BNST, BLA, or MD-thalamus caused a significant disruption of PPI, demonstrating that direct stimulation of NE receptors in these sites reproduces the deficit in information processing that is seen in multiple psychiatric illnesses including schizophrenia (Braff et al, 2001). These PPI deficits occurred with or without concomitant reductions in the startle response to the pulse-alone, indicating that simple alterations in baseline startle reactivity are not sufficient or necessary for $\mathrm{NE}$ receptor-mediated effects; instead, these effects reflect a veritable reduction in sensorimotor gating. Moreover, the $\alpha 1+\beta$-receptor-induced PPI deficit exhibited specificity for several discrete cortical and subcortical targets, rather than being promiscuously expressed in all sites tested; thus, for 


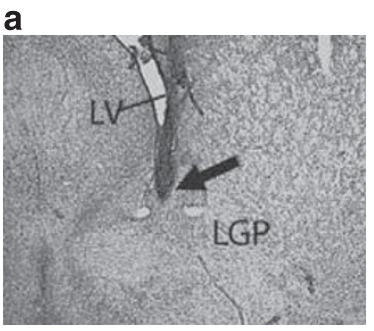

b

C

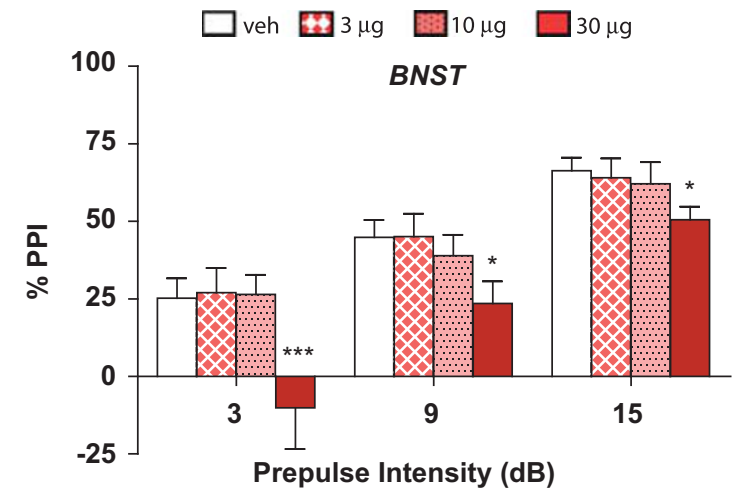

Figure 3 (a) Representative injector tip location within the bed nucleus of the stria terminalis (BNST), indicated by the arrow. LV, lateral ventricle; LGP, lateral globus pallidus. (b) Charting depicting the locations in which infusions of the $\alpha \mid+\beta$-NE receptor agonist cocktail disrupted \% prepulse inhibition (PPI). Distance is in $\mathrm{mm}$ from the bregma. (c) Effects on \% PPI of the phenylephrine + isoproterenol cocktail in the BNST. Values represent means \pm SEM for each dose. Doses are in $\mu g / 0.5 \mu$ l. Prepulse intensity indicates decibels above the background noise level. $* P<0.05, * * * P<0.0$ I relative to $\mathrm{VEH}$ (vehicle) condition.

each site in which the agonist cocktail produced an effect, there was an adjacent control site in which the same infusion parameters had no behavioral effect. Nevertheless, in each of the 'negative' sites tested (anterior mPFC, NAccCo, CeA, and DH), stimulation of DA D2 receptors did disrupt PPI. This positive control manipulation reveals that the lack of NE effect in those sites was not because of a lack of functional significance for PPI modulation, but rather that there is a mechanistic difference between NE and DA signaling within those sites that underlies the dissociable effects of these two systems on PPI. In summary, the present results reveal a set of specific anatomical substrates that mediate the disruptions of PPI seen with systemic administration of NE receptor agonists (Alsene et al, 2006; Carasso et al, 1998; Swerdlow et al, 2006; Varty et al, 1999). Moreover, as LC stimulation disrupts PPI through downstream release of NE (Bakshi and Alsene, 2010), these findings provide the first demonstration of the specific NE terminal regions through which this effect might occur. Overall, these findings indicate novel pathways for the regulation of PPI that may be distinct from previously characterized DA-sensitive substrates.

Previous studies of $\mathrm{D} \beta \mathrm{H}$ immunoreactivity (the enzyme for NE synthesis used to identify NE-containing neurons) indicated that in every site in which the $\alpha 1+\beta$-NE receptor agonist cocktail disrupted PPI, there was an abundance of NE-containing fibers (terminals) (Baldo et al, 2003; Berridge et al, 1997; Delfs et al, 1998; Swanson and Hartman, 1975). Among the 'PPI-negative' regions for the cocktail infusion, only NAccCo lacked $\mathrm{D} \beta \mathrm{H}$ immunoreactivity; all other sites (anterior $\mathrm{mPFC}, \mathrm{DH}$, and $\mathrm{CeA}$ ) displayed intense labeling. This observation confirms that the sites identified with the present direct-agonist mapping approach have physiological relevance with regard to understanding the behavioral effects of endogenous NE transmission. Moreover, high concentrations of both $\alpha 1+\beta$-NE receptors are found in many of the sites (anterior $\mathrm{mPFC}, \mathrm{DH}$, and $\mathrm{CeA}$ ) in which the agonist cocktail had no effect on PPI (Pupo and Minneman, 2001; Rainbow et al, 1984; Swanson and Hartman, 1975; Young and Kuhar, 1980), and the dose range employed in the present study was sufficiently high to alter other behaviors in these 'PPI-null' sites (Azami et al, 2010; Ferry et al, 1999; Kerfoot et al, 2008). Hence, our negative results are not because of the use of behaviorally inactive doses. The most parsimonious explanation is that there is a veritable functional segregation across anatomical regions with regard to NE modulation of PPI.

The specific structures that were found in the present studies to support NE-mediated PPI deficits likely reflect nodes within a distinct network or networks that ultimately impinge on the pedunculopontine tegmental nucleus, which functions as a midbrain interface between forebrain cognitive processing and the brainstem startle circuit (Fendt et al, 2001; Koch et al, 1993; Swerdlow et al, 2001), and is regarded as the obligatory 'final pathway' for forebrain regulation of PPI. Two primary considerations are relevant to understanding these putative NE-sensitive networks. First, does NE signaling elicit differential effects on neuron firing, local circuit dynamics, or other relevant parameters in 'PPI-responsive' $v s$ 'PPI-null sites' that could explain the differential NE agonist effects in these sites? Recent information regarding the subcellular localization of $\alpha 1$ receptors in NAccSh suggests specific substrates through which NE signaling might shift excitatory and DA neurotransmission in sites that regulate PPI (Rommelfanger et al, 2009; Verheij and Cools, 2009). Although not all the regions examined in this study have been tested with regard to such substrates, there are some independent findings that hint at possible mechanisms for the differential effects of NE receptor agonists across these regions. For example, measuring short-term potentiation in amygdala slices, it was found that $\beta$-receptor stimulation with isoproterenol increases synaptic plasticity in the medial portions of this structure such as CeA, but decreases it in BLA (Watanabe et al, 1996). Similarly, in certain regions such as basal forebrain and amygdala, $\alpha 1-$ and $\beta$-NE receptors produce additive effects or work in concert to support behavioral functions (Berridge, 2008; Ferry et al, 1999), but in cortical areas, these receptor subtypes can have opposing actions (Kobayashi, 2007). Thus, the net result of co-stimulating $\alpha 1$ and $\beta$-receptors (as would occur with endogenous enhancement of NE transmission) can vary across brain regions, and functional neuropharmacological differences such as these could represent the basis for the divergent efficacy of our NE direct agonist cocktail across the brain sites tested. Nevertheless, such factors cannot entirely account for the anatomical profile obtained in the present studies, as sites such as anterior $v s$ posterior mPFC likely share similar $\alpha 1$ - and $\beta$-receptor dynamics.

Thus, a second mechanism that could explain the divergent efficacy across sites of the $\alpha 1+\beta$-receptor cocktail 


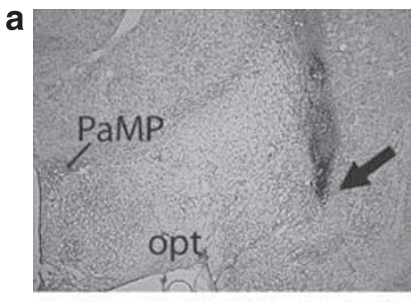

b
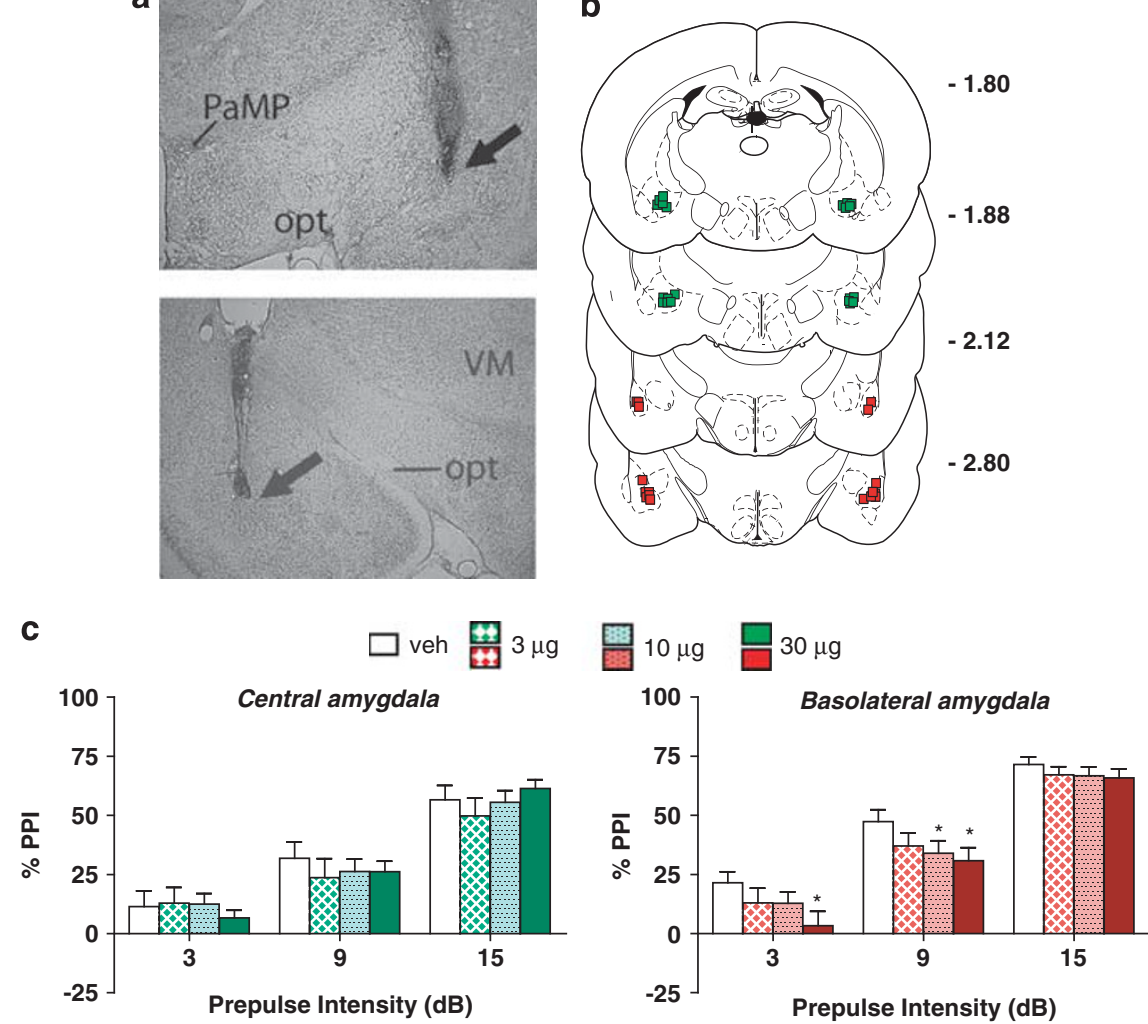

Figure 4 (a) Representative injector tip locations within the central amygdala (CeA) (top panel), and the basolateral amygdala (BLA) (bottom panel), indicated by the arrows. PaMP, paraventricular hypothalamic nucleus (medial part); opt, optic tract; VM, ventromedial thalamic nucleus. (b) Chartings depicting the locations in which infusions of the $\alpha \mid+\beta$-NE receptor agonist cocktail did (red) and did not (green) disrupt \% prepulse inhibition (PPI). Distances are in mm from the bregma. (c) Effects on \% PPI of the phenylephrine + isoproterenol cocktail in the CeA and the BLA. Values represent means \pm SEM for each dose. Doses are in $\mu \mathrm{g} / 0.5 \mu$ l. Prepulse intensity indicates decibels above the background noise level. $* P<0.05$, relative to $V E H$ (vehicle) condition.

is the differing input-output circuitry of these regions. All of the 'PPI-positive' sites fall into one of two putative anatomical circuits, a ventral forebrain network (with NAccSh and BNST), or a thalamocortical network (with posterior mPFC, BLA, and MD-thalamus). These two networks can be distinguished based on the sources of their afferent NE innervation as well as the magnitude of PPI disruption that was produced by NE receptor stimulation. One pattern that emerges is that sites subserving a more modest NE-based PPI disruption (ie, effects seen only with the highest dose and only at some prepulse intensities) receive $\mathrm{NE}$ innervation primarily from the $\mathrm{A} 1 / \mathrm{A} 2$ cell bodies (nucleus of the solitary tract) with far lesser contributions from the A6 cell bodies of the LC (Berridge et al, 1997; Delfs et al, 1998; Terenzi and Ingram, 1995). This pattern might suggest that the types of stimuli that drive A1/A2 nuclei (largely related to ascending visceral and autonomic information) do not exert as strong an effect on sensorimotor gating through these ascending NE projections.

In contrast, sites within our proposed thalamocortical circuit (BLA, posterior $\mathrm{MPFC}$, and MD-thalamus) receive all NE innervation from the LC (Foote et al, 1983; Swanson and Hartman, 1975). Of particular interest in this regard is the MD-thalamus. We found that $\mathrm{NE}$ agonists produce a profound PPI disruption in this site; indeed, this effect was the strongest and most dose-dependent out of all the sites tested. Interestingly, the BLA and posterior MPFC both connect reciprocally with MD-thalamus; robust NE agonistinduced PPI deficits were found in these sites, but not in the $\mathrm{DH}$, which does not connect to MD-thalamus (Gabbott et al, 2005; Giguere and Goldman-Rakic, 1988; Hoover and Vertes, 2007; Kuroda, 1998; Miyashita et al, 2007; Montagnese et al, 2003; Vertes et al, 2007). Moreover, the anterior mPFC, which was a 'null' site in this study, has proportionately less abundant reciprocal connections with MD-thalamus, compared with the posterior $\mathrm{mPFC}$, which was a 'PPI-active' site (Gabbott et al, 2005; Hoover and Vertes, 2007). Hence, the BLA, posterior MPFC, and MDthalamus may represent nodes within a reciprocally interconnected network by which affectively valenced processing in frontotemporal structures gains access to a thalamic relay for PPI, the MD-thalamus. Accordingly, when NE receptors are stimulated in sites within this thalamocortical network, a larger PPI disruption is seen than with the ventral forebrain regions, with multiple doses of the NE agonist cocktail being effective at all prepulse intensities in the BLA, posterior $\mathrm{MPFC}$, and, in particular, the MD-thalamus. The magnitude of the PPI deficit with NE receptor stimulation in MD-thalamus is similar to that seen with LC stimulation, which disrupts PPI via downstream release of NE (Bakshi and Alsene, 2010). Thus, a reciprocally interacting thalamocortical network with a strong NE projection from LC to MD-thalamus could be recruited by LC stimulation, and produce profound deficits 

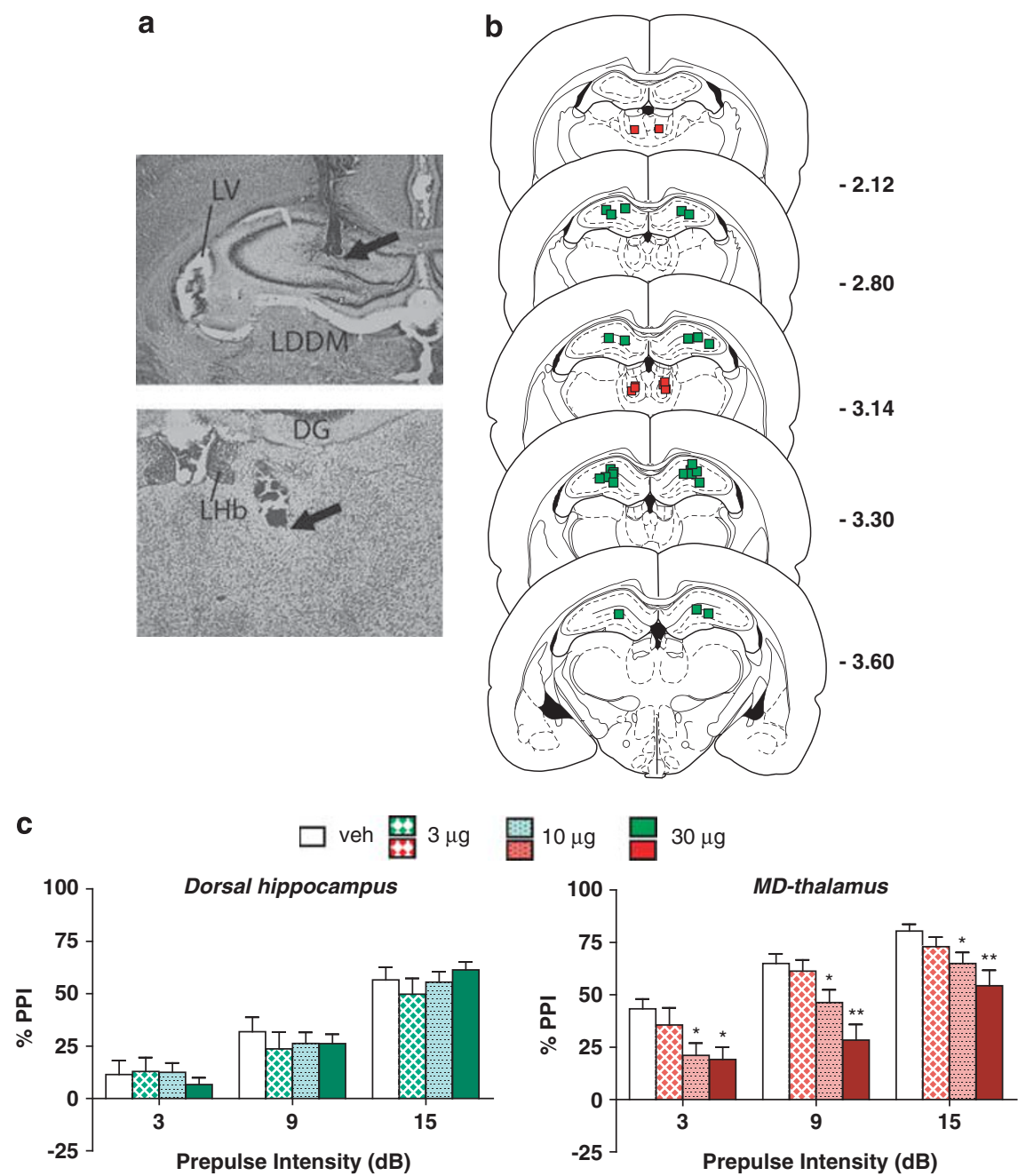

Figure 5 (a) Representative injector tip locations within the dorsal hippocampus (DH) (top panel) and the mediodorsal (MD) thalamus (bottom panel), indicated by the arrows. LV, lateral ventricle; LDDM, laterodorsal thalamic nucleus; DG, dentate gyrus; LHb, lateral habenular nucleus. (b) Chartings depicting the locations in which infusions of the $\alpha \mid+\beta$-NE receptor agonist cocktail did (red) and did not (green) disrupt \% prepulse inhibition (PPI). Distances are in $\mathrm{mm}$ from the bregma. (c) Effects on \% PPI of the phenylephrine + isoproterenol cocktail in the DH and the MD- thalamus. Values represent means \pm SEM for each dose. Doses are in $\mu g / 0.5 \mu$ l. Prepulse intensity indicates decibels above the background noise level. $* P<0.05$, $* * P<0.00$ I, relative to VEH (vehicle) condition.

in PPI because of connections with other neocortical sites such as BLA and posterior mPFC.

Interestingly, lesions or pharmacological inactivation of MD-thalamus disrupt PPI, but intra-MD-thalamus infusions of DA agonists do not, suggesting that this site regulates PPI independently of the DA system (Kodsi and Swerdlow, 1997; Swerdlow et al, 2002). The present results for the first time indicate a specific neurotransmitter system (NE) through which MD-thalamus regulation of PPI occurs, and raise the question of whether $\mathrm{NE}$ receptor stimulation in MDthalamus disrupts PPI by functionally inactivating this nucleus. Although thalamus is known to contain particularly high levels of $\alpha 1$-receptors (McCune et al, 1993; Pieribone et al, 1994; Strazielle et al, 1999), the cellular and ultrastructural localization of $\mathrm{NE}$ receptors specifically within the MD nucleus is not known, thus it is unclear whether these receptors are positioned to shift the balance of excitatory $v s$ inhibitory transmission within this site as they have been hypothesized to do in ventral striatum (Rommelfanger et al, 2009). Nevertheless, there is some evidence to suggest that in some thalamic regions, NE receptor stimulation can depress the firing rate of up to $90 \%$ of responsive neurons (Grasso et al, 2006). Whether these mechanisms also apply to the MD-thalamus remains to be determined, as the nature of NE-mediated electrophysiological responses in thalamus is exquisitely dependent on local transmitter concentration as well as cell type (McCormick et al, 1991; Moxon et al, 2007), but the notion that the present PPI disruption is due to a functional reduction of MD-thalamus activity is certainly a plausible hypothesis that merits further investigation. MD-thalamus does receive dense NE-containing projections that are distributed throughout the nucleus, and are even more abundant than the DA innervation of this site (Melchitzky and Lewis, 2001), so there is an additional anatomical basis for hypothesizing that within the MD-thalamus, NE transmission may be a crucial modulator of sensorimotor gating.

Cellular and neurotransmission abnormalities have been found in schizophrenia patients in several of the brain 

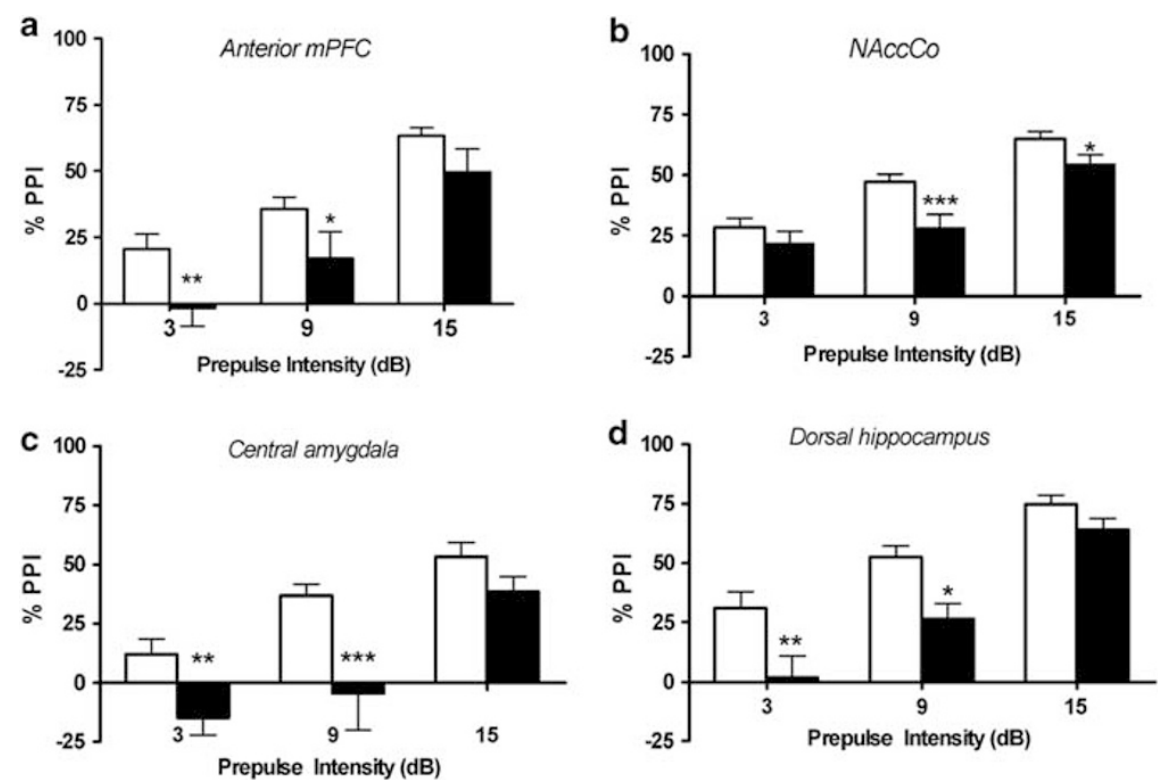

Figure 6 Effects on \% prepulse inhibition (PPI) of treatment with the dopamine receptor agonist quinpirole in the (a) anterior mPFC, (b) nucleus accumbens core, (c) central amygdala, and (d) dorsal hippocampus. Values represent means \pm SEM for each drug condition. White bars are vehicle values and black bars are values for quinpirole $(10 \mu \mathrm{g} / 0.5 \mu \mathrm{l})$. Prepulse intensity indicates decibels above the background noise level. $* P<0.05, * * P<0.0 \mathrm{I}$, $* * * P<0.00$ I relative to vehicle condition.

Table I Effects on Baseline Startle Magnitude (Responses to the I 20-dB Pulse-Alone Trials) of the Cocktail Solution of the $\alpha$ I-Receptor Agonist Phenylephrine Plus the $\beta$-Receptor Agonist Isoproterenol

\begin{tabular}{llccc}
\hline & Vehicle & $\begin{array}{c}\mathbf{3} \boldsymbol{\mu g} \\
\text { Cocktail }\end{array}$ & $\begin{array}{c}\mathbf{1 0} \boldsymbol{\mu g} \\
\text { Cocktail }\end{array}$ & $\begin{array}{c}\mathbf{3 0} \boldsymbol{\mu g} \\
\text { Cocktail }\end{array}$ \\
\hline Anterior mPFC & $294 \pm 43$ & $337 \pm 24$ & $275 \pm 43$ & $261 \pm 40$ \\
Posterior mPFC & $177 \pm 20$ & $196 \pm 19$ & $169 \pm 33$ & $123 \pm 21 *$ \\
NAccSh & $280 \pm 30$ & $243 \pm 53$ & $229 \pm 38$ & $177 \pm 26$ \\
NAccCo & $380 \pm 42$ & $388 \pm 43$ & $346 \pm 32$ & $361 \pm 47$ \\
BNST & $416 \pm 92$ & $393 \pm 89$ & $298 \pm 62$ & $208 \pm 59 *$ \\
Central amygdala & $418 \pm 66$ & $373 \pm 57$ & $355 \pm 50$ & $288 \pm 42 *$ \\
Basolateral amygdala & $409 \pm 41$ & $390 \pm 37$ & $368 \pm 50$ & $299 \pm 46 *$ \\
MD-thalamus & $512 \pm 199$ & $303 \pm 54$ & $235 \pm 37$ & $231 \pm 40$ \\
Dorsal hippocampus & $326 \pm 55$ & $341 \pm 60$ & $350 \pm 61$ & $326 \pm 71$ \\
\hline
\end{tabular}

Doses are in $\mu \mathrm{g} / 0.5 \mu \mathrm{l}$. Values represent means \pm SEM for each dose. $* P<0.05$, relative to vehicle condition.

regions identified presently to mediate NE-based sensorimotor gating deficits, including MD-thalamus (Alelu-Paz and Gimenez-Amaya, 2008; Byne et al, 2009; Lewis, 2009; Pakkenberg et al, 2009), and analysis of MD-thalamus-PFC innervation at the ultrastructural level has led to the suggestion that this site is well positioned to 'gate' information processing within PFC (Rotaru et al, 2005), a process that may be intimately connected to PPI. Hence, the MD-thalamus may represent an important site of action for second-generation ('atypical') antipsychotic drugs that act in part through DA-independent mechanisms such as $\alpha 1$-NE receptors (Bymaster et al, 1996), since secondgeneration antipsychotics are particularly effective in
Table 2 Effects on Baseline Startle Magnitude (Responses to the I20-dB Pulse-Alone Trials) of the Dopamine D2 Receptor Agonist Quinpirole $(\mid 0 \mu \mathrm{g} / 0.5 \mu \mathrm{l})$

\begin{tabular}{lcc}
\hline & Vehicle & I0 $\boldsymbol{\text { Hg Quinpirole }}$ \\
\hline Anterior mPFC & $315 \pm 35$ & $217 \pm 31^{*}$ \\
NAccCo & $408 \pm 49$ & $163 \pm 38^{*}$ \\
Central amygdala & $394 \pm 53$ & $309 \pm 44$ \\
Dorsal hippocampus & $254 \pm 40$ & $164 \pm 21 *$ \\
\hline
\end{tabular}

Values represent means \pm SEM for each dose. $* P<0.05$, relative to vehicle condition.

normalizing NE-based PPI deficits that are induced by stimulation of the LC (Bakshi and Alsene, 2010).

$\alpha 1$ - and $\beta$-receptors in multiple forebrain sites have long been known to participate in higher-order cognitive tasks such as working memory and attentional set-shifting via mPFC (Arnsten et al, 1999, 1998; Lapiz and Morilak, 2006; Ramos et al, 2005, 2006), and learning and memory processes via hippocampus and amygdala (Ferry et al, 1999; Miranda et al, 2007; Roozendaal et al, 2004, 2008). The present results considerably broaden this view of the functional role of NE receptors in cognition by providing for the first time a systematic delineation of the extended neuronal network through which NE signaling can regulate pre-attentional forms of information processing such as PPI. Given the conceptualization of sensorimotor gating as a breakdown in information filtering that can result in the processing of potentially irrelevant stimuli (Braff et al, 2008; Swerdlow et al, 2008), it is tempting to speculate that NE receptor-mediated deficits in PPI might contribute to impairments in volitional attention-based tasks such as delayed alternation paradigms by allowing too much 
(potentially irrelevant) information to gain access and compete with task-relevant information held online in frontotemporal networks. The present results are also consistent with theories that altered forebrain NE transmission contributes to the cognitive deficits seen in schizophrenia patients (Robbins and Arnsten, 2009).

These findings have implications for all psychiatric diseases that involve deficient sensorimotor gating. Schizophrenia is often considered the prime example of these diseases; however, Tourette syndrome and post-traumatic stress disorder (PTSD) are also reliably associated with disrupted PPI (Braff et al, 2001; Castellanos et al, 1996; Grillon et al, 1996; Swerdlow, 2001). These disorders are well known to be responsive to NE-based drugs and potentially involve dysregulation of the NE system (Bhidayasiri, 2005; Breier et al, 1990; Gay et al, 1989; Gomes et al, 1980; Leckman et al, 1995; Sandyk, 1986). Therefore, it is possible that increased NE signaling at $\alpha 1-$ and $\beta$-receptors in regions such as posterior mPFC, NAccSh, BNST, BLA, and MD-thalamus could contribute to the pathophysiology of these psychiatric disorders. Indeed, the $\alpha 1-\mathrm{NE}$ receptor antagonist prazosin and drugs such as guanfacine and clonidine that reduce $\mathrm{NE}$ transmission via stimulation of $\alpha 2$-NE autoreceptors completely block NEbased PPI deficits (Alsene et al, 2006; Carasso et al, 1998; Swerdlow et al, 2006) and are effective in treating PTSD and Tourette syndrome (Daly et al, 2005; Leckman et al, 1991), leading to the suggestion that NE-based models of PPI deficits may be particularly relevant for these illnesses (Swerdlow et al, 2006). Thus, normalization of NE signaling at $\alpha 1$ - and $\beta$-receptors within nodes of these frontotemporal PPI networks could have beneficial effects on sensorimotor gating deficits in a number of psychiatric illnesses in which deficient PPI is considered a core endophenotype.

\section{ACKNOWLEDGEMENTS}

This work was supported by T32GM007507, R01-MH075980 (VPB) and F31-MH077465 (KMA). We thank Dr Brian Baldo for his helpful comments on the paper.

\section{DISCLOSURE}

The authors declare no conflict of interest. Dr Alsene is currently a Medical Writer for Takeda, but this position has no relationship with the work in this paper, which was completed before her employment at Takeda.

\section{REFERENCES}

Alelu-Paz R, Gimenez-Amaya JM (2008). The mediodorsal thalamic nucleus and schizophrenia. J Psychiatry Neurosci 33: 489-498.

Alsene KM, Carasso BS, Connors EE, Bakshi VP (2006). Disruption of prepulse inhibition after stimulation of central but not peripheral alpha-1 adrenergic receptors. Neuropsychopharmacology 31: 2150-2161.

Arnsten AF (2004). Adrenergic targets for the treatment of cognitive deficits in schizophrenia. Psychopharmacology (Berl) 174: $25-31$.
Arnsten AF, Mathew R, Ubriani R, Taylor JR, Li BM (1999). Alpha-1 noradrenergic receptor stimulation impairs prefrontal cortical cognitive function. Biol Psychiatry 45: 26-31.

Arnsten AF, Steere JC, Jentsch DJ, Li BM (1998). Noradrenergic influences on prefrontal cortical cognitive function: opposing actions at postjunctional alpha $1 v s$ alpha 2-adrenergic receptors. Adv Pharmacol 42: 764-767.

Aston-Jones G, Cohen JD (2005). Adaptive gain and the role of the locus coeruleus-norepinephrine system in optimal performance. J Comp Neurol 493: 99-110.

Azami NS, Piri M, Oryan S, Jahanshahi M, Babapour V, Zarrindast MR (2010). Involvement of dorsal hippocampal alpha-adrenergic receptors in the effect of scopolamine on memory retrieval in inhibitory avoidance task. Neurobiol Learn Mem 93: 455-462.

Bakshi VP, Alsene KM (2010). Locus coeruleus: A novel substrate in the regulation of sensorimotor gating. Neuropsychopharmacology 35: S292.

Baldo BA, Daniel RA, Berridge CW, Kelley AE (2003). Overlapping distributions of orexin/hypocretin- and dopamine-beta-hydroxylase immunoreactive fibers in rat brain regions mediating arousal, motivation, and stress. J Comp Neurol 464: 220-237.

Berridge CW (2008). Noradrenergic modulation of arousal. Brain Res Rev 58: 1-17.

Berridge CW, Isaac SO, Espana RA (2003). Additive wakepromoting actions of medial basal forebrain noradrenergic alpha1- and beta-receptor stimulation. Behav Neurosci 117: 350-359.

Berridge CW, Stratford TL, Foote SL, Kelley AE (1997). Distribution of dopamine beta-hydroxylase-like immunoreactive fibers within the shell subregion of the nucleus accumbens. Synapse 27: 230-241.

Berridge CW, Waterhouse BD (2003). The locus coeruleusnoradrenergic system: modulation of behavioral state and state-dependent cognitive processes. Brain Res Brain Res Rev 42: 33-84.

Bhidayasiri R (2005). Tourette's syndrome: old syndrome, new insights and new treatment. J Med Assoc Thai 88(Suppl 4): S339-S347.

Braff DL, Geyer MA, Swerdlow NR (2001). Human studies of prepulse inhibition of startle: normal subjects, patient groups, and pharmacological studies. Psychopharmacology (Berl) 156: 234-258.

Braff DL, Greenwood TA, Swerdlow NR, Light GA, Schork NJ (2008). Advances in endophenotyping schizophrenia. World Psychiatry 7: 11-18.

Breier A, Wolkowitz OM, Roy A, Potter WZ, Pickar D (1990). Plasma norepinephrine in chronic schizophrenia. Am J Psychiatry 147: 1467-1470.

Bylund DB, Eikenberg DC, Hieble JP, Langer SZ, Lefkowitz RJ, Minneman KP et al (1994). International Union of Pharmacology nomenclature of adrenoceptors. Pharmacol Rev 46: 121-136.

Bymaster FP, Calligaro DO, Falcone JF, Marsh RD, Moore NA, Tye NC et al (1996). Radioreceptor binding profile of the atypical antipsychotic olanzapine. Neuropsychopharmacology 14: 87-96.

Byne W, Hazlett EA, Buchsbaum MS, Kemether E (2009). The thalamus and schizophrenia: current status of research. Acta Neuropathol 117: 347-368.

Carasso BS, Bakshi VP, Geyer MA (1998). Disruption in prepulse inhibition after alpha-1 adrenoceptor stimulation in rats. Neuropharmacology 37: 401-404.

Castellanos FX, Fine EJ, Kaysen D, Marsh WL, Rapoport JL, Hallett M (1996). Sensorimotor gating in boys with Tourette's syndrome and ADHD: preliminary results. Biol Psychiatry 39: 33-41.

Daly CM, Doyle ME, Radkind M, Raskind E, Daniels C (2005). Clinical case series: the use of Prazosin for combat-related recurrent nightmares among Operation Iraqi Freedom combat veterans. Mil Med 170: 513-515.

Delfs JM, Zhu Y, Druhan JP, Aston-Jones GS (1998). Origin of noradrenergic afferents to the shell subregion of the nucleus 
accumbens: anterograde and retrograde tract-tracing studies in the rat. Brain Res 806: 127-140.

Dvorakova M, Jezova D, Blazicek P, Trebaticka J, Skodacek I, Suba J et al (2007). Urinary catecholamines in children with attention deficit hyperactivity disorder (ADHD): modulation by a polyphenolic extract from pine bark (pycnogenol). Nutr Neurosci 10: 151-157.

Fendt M, Li L, Yeomans JS (2001). Brain stem circuits mediating prepulse inhibition of the startle reflex. Psychopharmacology (Berl) 156: 216-224.

Ferry B, Roozendaal B, McGaugh JL (1999). Involvement of alpha1adrenoceptors in the basolateral amygdala in modulation of memory storage. Eur J Pharmacol 372: 9-16.

Foote SL, Bloom FE, Aston-Jones G (1983). Nucleus locus ceruleus: new evidence of anatomical and physiological specificity. Physiol Rev 63: 844-914.

Gabbott PL, Warner TA, Jays PR, Salway P, Busby SJ (2005). Prefrontal cortex in the rat: projections to subcortical autonomic, motor, and limbic centers. J Comp Neurol 492: 145-177.

Gay N, Cottraux JA, Denoroy L, Tommasi M, Kopp N (1989). Possible increase of dopamine-beta-hydroxylase activity in the locus ceruleus of paranoid schizophrenic patients: a preliminary post-mortem study. Psychiatry Res 27: 31-38.

Geyer MA (2008). Developing translational animal models for symptoms of schizophrenia or bipolar mania. Neurotox Res 14: 71-78.

Geyer MA, Krebs-Thomson K, Braff DL, Swerdlow NR (2001). Pharmacological studies of prepulse inhibition models of sensorimotor gating deficits in schizophrenia: a decade in review. Psychopharmacology (Berl) 156: 117-154.

Geyer MA, Swerdlow NR, Mansbach RS, Braff DL (1990). Startle response models of sensorimotor gating and habituation deficits in schizophrenia. Brain Res Bull 25: 485-498.

Giguere M, Goldman-Rakic PS (1988). Mediodorsal nucleus: areal, laminar, and tangential distribution of afferents and efferents in the frontal lobe of rhesus monkeys. J Comp Neurol 277: 195-213.

Gomes UC, Shanley BC, Potgieter L, Roux JT (1980). Noradrenergic overactivity in chronic schizophrenia: evidence based on cerebrospinal fluid noradrenaline and cyclic nucleotide concentrations. Br J Psychiatry 137: 346-351.

Grasso C, Li Volsi G, Licata F, Ciranna L, Santangelo F (2006). Aminergic control of neuronal firing rate in thalamic motor nuclei of the rat. Arch Ital Biol 144: 173-196.

Grillon C, Morgan CA, Southwick SM, Davis M, Charney DS (1996). Baseline startle amplitude and prepulse inhibition in Vietnam veterans with posttraumatic stress disorder. Psychiatry Res 64: 169-178.

Hoover WB, Vertes RP (2007). Anatomical analysis of afferent projections to the medial prefrontal cortex in the rat. Brain Struct Funct 212: 149-179.

Hornykiewicz O (1982). Brain catecholamines in schizophrenia - a good case for noradrenaline. Nature 299: 484-486.

Kerfoot EC, Chattillion EA, Williams CL (2008). Functional interactions between the nucleus tractus solitarius (NTS) and nucleus accumbens shell in modulating memory for arousing experiences. Neurobiol Learn Mem 89: 47-60.

Kobayashi M (2007). Differential regulation of synaptic transmission by adrenergic agonists via protein kinase $\mathrm{A}$ and protein kinase $\mathrm{C}$ in layer $\mathrm{V}$ pyramidal neurons of rat cerebral cortex. Neuroscience 146: 1772-1784.

Koch M, Kungel M, Herbert H (1993). Cholinergic neurons in the pedunculopontine tegmental nucleus are involved in the mediation of prepulse inhibition of the acoustic startle response in the rat. Exp Brain Res 97: 71-82.

Kodsi MH, Swerdlow NR (1997). Regulation of prepulse inhibition by ventral pallidal projections. Brain Res Bull 43: 219-228.

Kuroda M (1998). Synaptic connections between the prefrontal cortex and the mediodorsal nucleus of the thalamus. Kaibogaku Zasshi 73: 93-106.
Lahdesmaki J, Sallinen J, MacDonald E, Kobilka BK, Fagerholm V, Scheinin M (2002). Behavioral and neurochemical characterization of alpha(2A)-adrenergic receptor knockout mice. Neuroscience 113: 289-299.

Lahdesmaki J, Sallinen J, MacDonald E, Scheinin M (2004). Alpha2A-adrenoceptors are important modulators of the effects of $\mathrm{D}$-amphetamine on startle reactivity and brain monoamines. Neuropsychopharmacology 29: 1282-1293.

Lapiz MD, Morilak DA (2006). Noradrenergic modulation of cognitive function in rat medial prefrontal cortex as measured by attentional set shifting capability. Neuroscience 137: 1039-1049.

Leckman JF, Goodman WK, Anderson GM, Riddle MA, Chappell PB, McSwiggan-Hardin MT et al (1995). Cerebrospinal fluid biogenic amines in obsessive compulsive disorder, Tourette's syndrome, and healthy controls. Neuropsychopharmacology 12: 73-86.

Leckman JF, Hardin MT, Riddle MA, Stevenson J, Ort SI, Cohen DJ (1991). Clonidine treatment of Gilles de la Tourette's syndrome. Arch Gen Psychiatry 48: 324-328.

Lewis DA (2009). Neuroplasticity of excitatory and inhibitory cortical circuits in schizophrenia. Dialogues Clin Neurosci 11: 269-280.

Mansbach RS, Geyer MA, Braff DL (1988). Dopaminergic stimulation disrupts sensorimotor gating in the rat. Psychopharmacology (Berl) 94: 507-514.

McCormick DA, Pape HC, Williamson A (1991). Actions of norepinephrine in the cerebral cortex and thalamus: implications for function of the central noradrenergic system. Prog Brain Res 88: 293-305.

McCune SK, Voigt MM, Hill JM (1993). Expression of multiple alpha adrenergic receptor subtype messenger RNAs in the adult rat brain. Neuroscience 57: 143-151.

Melchitzky DS, Lewis DA (2001). Dopamine transporter-immunoreactive axons in the mediodorsal thalamic nucleus of the macaque monkey. Neuroscience 103: 1033-1042.

Miranda MA, Ferry B, Ferreira G (2007). Basolateral amygdala noradrenergic activity is involved in the acquisition of conditioned odor aversion in the rat. Neurobiol Learn Mem 88: 260-263.

Miyashita T, Ichinohe N, Rockland KS (2007). Differential modes of termination of amygdalothalamic and amygdalocortical projections in the monkey. J Comp Neurol 502: 309-324.

Montagnese CM, Mezey SE, Csillag A (2003). Efferent connections of the dorsomedial thalamic nuclei of the domestic chick (Gallus domesticus). J Comp Neurol 459: 301-326.

Moxon KA, Devilbiss DM, Chapin JK, Waterhouse BD (2007). Influence of norepinephrine on somatosensory neuronal responses in the rat thalamus: a combined modeling and in vivo multi-channel, multi-neuron recording study. Brain Res 1147: $105-123$.

Nicholas AP, Hokfelt T, Pieribone VA (1996). The distribution and significance of CNS adrenoceptors examined with in situ hybridization. Trends Pharmacol Sci 17: 245-255.

Pakkenberg B, Scheel-Kruger J, Kristiansen LV (2009). Schizophrenia; from structure to function with special focus on the mediodorsal thalamic prefrontal loop. Acta Psychiatr Scand 120: 345-354.

Palacios J, Kuhar MJ (1982). Beta adrenergic receptor localization in rat brain by light microscopic autoradiography. Neurochem Int 4: 473-490.

Pieribone VA, Nicholas AP, Dagerlind A, Hokfelt T (1994). Distribution of alpha 1 adrenoceptors in rat brain revealed by in situ hybridization experiments utilizing subtype-specific probes. J Neurosci 14: 4252-4268.

Pupo AS, Minneman KP (2001). Adrenergic pharmacology: focus on the central nervous system. CNS Spectr 6: 656-662.

Rainbow TC, Parsons B, Wolfe BB (1984). Quantitative autoradiography of beta 1 - and beta 2 -adrenergic receptors in rat brain. Proc Natl Acad Sci USA 81: 1585-1589. 
Ramos BP, Colgan L, Nou E, Ovadia S, Wilson SR, Arnsten AF (2005). The beta-1 adrenergic antagonist, betaxolol, improves working memory performance in rats and monkeys. Biol Psychiatry 58: 894-900.

Ramos BP, Stark D, Verduzco L, van Dyck CH, Arnsten AF (2006). Alpha2A-adrenoceptor stimulation improves prefrontal cortical regulation of behavior through inhibition of cAMP signaling in aging animals. Learn Mem 13: 770-776.

Robbins TW, Arnsten AF (2009). The neuropsychopharmacology of fronto-executive function: monoaminergic modulation. Annu Rev Neurosci 32: 267-287.

Rommelfanger KS, Mitrano DA, Smith Y, Weinshenker D (2009). Light and electron microscopic localization of alpha-1 adrenergic receptor immunoreactivity in the rat striatum and ventral midbrain. Neuroscience 158: 1530-1540.

Roozendaal B, Castello NA, Vedana G, Barsegyan A, McGaugh JL (2008). Noradrenergic activation of the basolateral amygdala modulates consolidation of object recognition memory. Neurobiol Learn Mem 90: 576-579.

Roozendaal B, Hahn EL, Nathan SV, de Quervain DJ, McGaugh JL (2004). Glucocorticoid effects on memory retrieval require concurrent noradrenergic activity in the hippocampus and basolateral amygdala. J Neurosci 24: 8161-8169.

Rotaru DC, Barrionuevo G, Sesack SR (2005). Mediodorsal thalamic afferents to layer III of the rat prefrontal cortex: synaptic relationships to subclasses of interneurons. J Comp Neurol 490: 220-238.

Sallinen J, Haapalinna A, Viitamaa T, Kobilka BK, Scheinin M (1998). Adrenergic alpha2C-receptors modulate the acoustic startle reflex, prepulse inhibition, and aggression in mice. J Neurosci 18: 3035-3042.

Sandyk R (1986). Tourette syndrome: a case for noradrenergic and opiatergic mechanisms. Int J Neurosci 30: 303-309.

Sara SJ (2009). The locus coeruleus and noradrenergic modulation of cognition. Nat Rev Neurosci 10: 211-223.

Schwabe K, Koch M (2004). Role of the medial prefrontal cortex in $\mathrm{N}$-methyl-D-aspartate receptor antagonist induced sensorimotor gating deficit in rats. Neurosci Lett 355: 5-8.

Southwick SM, Krystal JH, Morgan CA, Johnson D, Nagy LM, Nicolaou A et al (1993). Abnormal noradrenergic function in posttraumatic stress disorder. Arch Gen Psychiatry 50: 266-274.

Strazielle C, Lalonde R, Hebert C, Reader TA (1999). Regional brain distribution of noradrenaline uptake sites, and of alpha1alpha2- and beta-adrenergic receptors in PCD mutant mice: a quantitative autoradiographic study. Neuroscience 94: 287-304.
Swanson LW, Hartman BK (1975). The central adrenergic system. An immunofluorescence study of the location of cell bodies and their efferent connections in the rat utilizing dopamine-betahydroxylase as a marker. J Comp Neurol 163: 467-505.

Swerdlow NR (2001). Obsessive-compulsive disorder and tic syndromes. Med Clin North Am 85: 735-755.

Swerdlow NR, Bongiovanni MJ, Tochen L, Shoemaker JM (2006). Separable noradrenergic and dopaminergic regulation of prepulse inhibition in rats: implications for predictive validity and Tourette syndrome. Psychopharmacology (Berl) 186: 246-254.

Swerdlow NR, Geyer MA, Braff DL (2001). Neural circuit regulation of prepulse inhibition of startle in the rat: current knowledge and future challenges. Psychopharmacology (Berl) 156: 194-215.

Swerdlow NR, Pitcher L, Noh HR, Shoemaker JM (2002). Startle gating in rats is disrupted by chemical inactivation but not D2 stimulation of the dorsomedial thalamus. Brain Res 953: 246-254.

Swerdlow NR, Weber M, Qu Y, Light GA, Braff DL (2008). Realistic expectations of prepulse inhibition in translational models for schizophrenia research. Psychopharmacology (Berl) 199: 331-388.

Terenzi MG, Ingram CD (1995). A combined immunocytochemical and retrograde tracing study of noradrenergic connections between the caudal medulla and bed nuclei of the stria terminalis. Brain Res 672: 289-297.

Varty GB, Bakshi VP, Geyer MA (1999). M100907, a serotonin 5-HT2A receptor antagonist and putative antipsychotic, blocks dizocilpine-induced prepulse inhibition deficits in SpragueDawley and Wistar rats. Neuropsychopharmacology 20: 311-321.

Verheij MM, Cools AR (2009). Accumbal noradrenaline that contributes to the alpha-adrenoceptor-mediated release of dopamine from reserpine-sensitive storage vesicles in the nucleus accumbens is derived from alpha-methyl-para-tyrosine-sensitive pools. J Neural Transm 116: 389-394.

Vertes RP, Hoover WB, Szigeti-Buck K, Leranth C (2007). Nucleus reuniens of the midline thalamus: link between the medial prefrontal cortex and the hippocampus. Brain Res Bull 71: 601-609.

Watanabe Y, Ikegaya Y, Saito H, Abe K (1996). Opposite regulation by the beta-adrenoceptor-cyclic AMP system of synaptic plasticity in the medial and lateral amygdala in vitro. Neuroscience 71: 1031-1035.

Young III WS, Kuhar MJ (1980). Noradrenergic alpha 1 and alpha 2 receptors: light microscopic autoradiographic localization. Proc Natl Acad Sci USA 77: 1696-1700. 